\title{
Identificação e classificação de elementos da paisagem urbana em espaços públicos da cidade
}

Identification and classification of urban landscape elements in public spaces of the city

Identificación y clasificación de elementos del paisaje urbano en espacios públicos de la ciudad

Beatriz Figueiredo Eschholz Mestranda em Planejamento Urbano e Territorial, Politecnico di Torino, Italia bfigueiredoo@gmail.com

\section{Luciana Marcia Gonçalves} Professora Doutora, UFSCar, Brasil. arq.luciana.ufscar@gmail.com

Rochele Amorim Ribeiro Professora Doutora, UFSCar, Brasil. ribeirorochele@gmail.com 


\section{RESUMO}

Este artigo analisa elementos paisagísticos e aspectos vivenciais em espaços públicos urbanos. Aplicou-se uma metodologia de análise em duas praças de São Carlos, Brasil, identificando e classificando elementos à luz de Cullen (1971) e Gehl (2010). A metodologia contempla análise de imagens, desenhos, visitas in loco e referências bibliográficas. As avaliações dos espaços são descritas de forma qualitativa e quantitativa, considerando a presença de elementos de valorização da paisagem, identificação da identidade de cada espaço por meio de percepções e utilizações e, por fim, sugestões para possíveis melhoramentos com inserção de atratividades. Os resultados contribuem para a construção de um método de análise de forma a obter ambientes de convivência mais agradáveis e habitáveis.

PALAVRAS-CHAVE: Espaços Públicos; Elementos Paisagísticos; Projetos Urbanos.

\section{ABSTRACT}

This article analyzes landscape elements and living aspects in urban areas. The methodology of analysis was used in two places of São Carlos, Brazil, identifying and classifying elements based on the concepts of Cullen (1971) and Gehl (2010). The methodology used includes analysis of images, drawings, visits in loco and bibliographical references. In the form of qualitative and quantitative tables, the results translated in an effective analysis for the Brazilian reality and created subsidies for urban projects in this context.

KEYWORDS: Public spaces, Landscapes elements, Urban projects.

\section{RESUMEN}

Este artículo analiza elementos paisajísticos y aspectos vivenciales en espacios públicos urbanos. Se aplicó una metodología de análisis en dos plazas de São Carlos, Brasil, identificando y clasificando elementos a la luz de Cullen (1971) y Gehl (2010). La metodología contempla análisis de imágenes, dibujos, visitas in loco y referencias bibliográficas. Las evaluaciones de los espacios se describen de forma cualitativa y cuantitativa, considerando la presencia de elementos de valorización del paisaje, identificación de la identidad de cada espacio por medio de percepciones y usos y, por último, sugerencias para posibles mejoras con inserción de atractividades. Los resultados contribuyen a la construcción de un método de análisis para obtener ambientes de convivencia más agradables y habitables.

PALABRAS CLAVE: Espacios públicos; Elementos Paisajísticos; Proyectos Urbanos. 


\section{INTRODUÇÃO E OBJETIVO}

Os espaços públicos, no contexto de criação de um ambiente urbano e onde se produz impressões nos indivíduos, possuem uma clara importância no cenário urbano, no cotidiano e no humor dos habitantes. Porém, muitas vezes, as cidades e seus espaços públicos se tornam, segundo Cullen (1971), "monótonos e incaracterísticos" e não adquirem o papel de agentes de reações emocionais, falhando na finalidade inicial de ser um espaço agradável e habitado.

Nessa circunstância, a análise e o emprego de elementos urbanísticos que tornem os espaços urbanos lugares mais habitáveis e com relações expressivas, estabelecem uma importante área de estudo. Aspectos como visualidades, identidades locais, relações morfológicas, os elementos abordados por Cullen (1971) e os critérios de qualidade de Gehl (2010) podem contribuir para uma maior compreensão da paisagem urbana e dos fenômenos que lhe dão origem, possibilitando classificar e identificar elementos paisagísticos em espaços públicos para apoio de projetos urbanos. Além disso, os conceitos de paisagem urbana de Cullen (1971) e Gehl (2010) compreendidos como meios de análise e observação são um recurso versátil para coleta de dados, informações e referências, especialmente pela interação promovida entre o ser humano e o ambiente urbano, estimulando a percepção à paisagem e às emoções dos indivíduos. Gehl (2010) moderniza a visão de Cullen (1971) e complementa os diversos elementos abordados em Paisagem Urbana.

Dessa forma, em busca de proporcionar uma melhoria nas cidades e afirmar a importância de espaços públicos para a composição da paisagem, a proposta deste artigo foi identificar e classificar elementos urbanísticos em duas praças de São Carlos-SP, para qualificar a paisagem urbana à luz dos conceitos e definições de Cullen (1971) e Gehl (2010), com a finalidade de subsidiar novos projetos urbanos.

\section{DEFINIÇÃO E CARACTERIZAÇÃO DOS CRITÉRIOS PARA O MÉTODO DE ANÁLISE DE ESPAÇOS PÚBLICOS}

Para a definição e caracterização dos critérios para análise, utilizou-se imagens, desenhos, visitas in loco e referências bibliográficas. Como método do trabalho, a primeira etapa consistiu na fundamentação teórica por meio do estudo conceitual de Cullen (1971) e de Gehl (2010). A partir disso, houve a análise técnica de elementos urbanísticos abordados, de modo a identificar métodos de suporte à classificação dos objetos de estudo. Em seguida, foi feito a estruturação e o estudo dos espaços, por meio do levantamento histórico, do perfil de uso das praças e da visita in loco, seguidos de uma sistematização em tabelas quantitativas e qualitativas. A terceira etapa constituiu-se na análise crítica dos resultados dessas tabelas elaboradas. Assim, o Quadro 1 sistematiza os critérios escolhidos dos dois autores e, de forma a exemplificar os elementos paisagísticos desses critérios, o Quadro 2 ilustra alguns deles em situações reais. 


\section{Revista Nacional de}

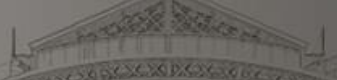

Quadro 1 Critérios escolhidos para classificação dos objetos de estudo

\begin{tabular}{|l|l|}
\hline \multicolumn{1}{|c|}{ Autor analisado } & \multicolumn{1}{|c|}{ Critérios } \\
\hline & 1) Ponto focal \\
\hline & 2) Delimitação do espaço \\
\hline & 3) Desníveis \\
\hline 4) Entrelaçamento \\
\hline 5) Perspectiva Grandiosa \\
\hline 6) Estreitamentos \\
\hline 7) Flutuação \\
\hline 8) Caminhos para pedestres \\
\hline 9) Edifício como escultura \\
\hline 10) Escala humana \\
\hline 1) Oportunidade para caminhar \\
\hline 2) Oportunidade para brincar e praticar atividade física \\
\hline 3) Oportunidades para permanecer em pé \\
\hline 4) Oportunidades para sentar-se \\
\hline 5) Oportunidades para ouvir e conversar \\
\hline 6) Proteção contra o crime e a violência \\
\hline 7) Escala humana \\
\hline
\end{tabular}

Fonte: AUTORES,2018 


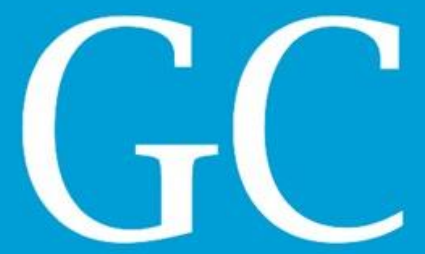

Revista Nacional de

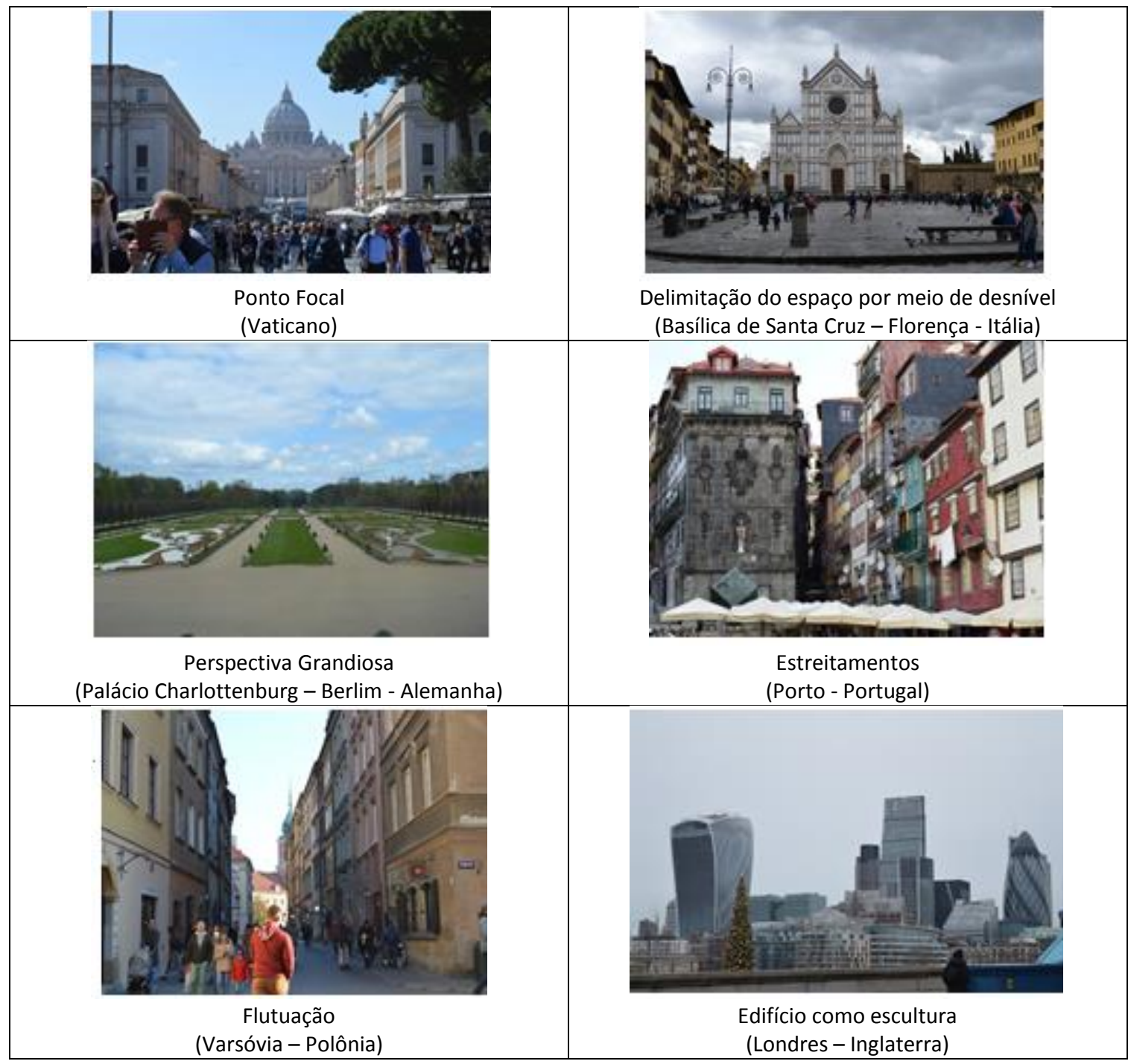

Fonte: AUTORES,2018

\section{OBJETOS DE ESTUDO}

Os objetos de estudo deste artigo consistem em duas praças situadas na cidade de São Carlos, SP, na Zona de Ocupação Consolidada, prevista pelo Plano Diretor do Município de São Carlos (SÃO CARLOS, 2016). Assim, estão localizadas na área central com grande concentração de serviços, empregos e comércios. Tal condição atesta a importância dessas praças como espaços integrantes do conjunto urbanístico a se preservar como patrimônio histórico, capaz de manter a identidade e a memória coletiva. Dessa forma, a escolha desses objetos deu-se por elas possuírem configurações urbanas distintas, grande importância na história da cidade e 


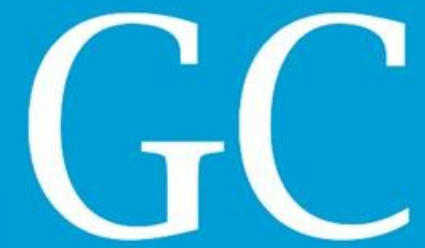

Revista Nacional de

serem decorrentes de momentos diferentes de urbanização. A Figura 1 identifica a localização das duas praças estudadas: a Praça Coronel Salles e a Praça Dr. Christiano Altenfelder Silva.

Figura 1: Localização das praças em São Carlos

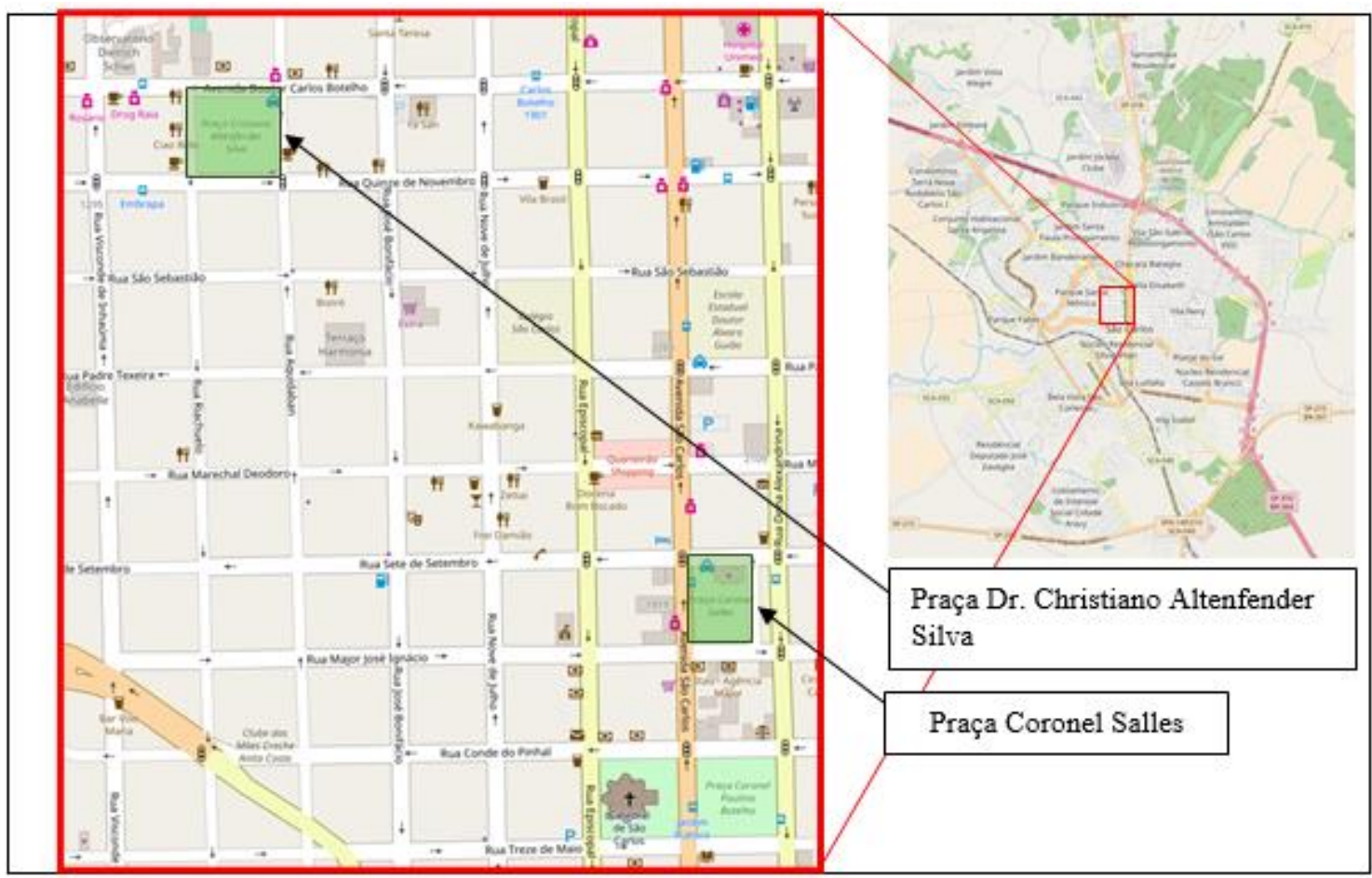

Fonte: OpenStreetMap,2018

A praça Dr. Christiano Altenfelder Silva, popularmente conhecida como praça XV de novembro, está localizada na área central da cidade, em um quadrilátero movimentado formado pela avenida Dr. Carlos Botelho e pelas ruas Aquidaban, Riachuelo e XV de Novembro. Foi criada em 1951 e foi muito usada anteriormente como palco dos circos da cidade. Atualmente, a praça é cercada por diversos estabelecimentos comerciais, residenciais e públicos, e apresenta grande fluxo de pessoas em alguns dias da semana, em razão de atrações musicais e de feiras organizadas.

Já a praça Coronel Salles, também conhecida popularmente como Praça dos Pombos, foi criada em 1921 e está localizada em um quadrilátero formado pela avenida São Carlos e pelas ruas Major José Inácio, Dona Alexandrina e Sete de setembro. Atualmente, possui em sua área diversos equipamentos públicos importantes como a Câmara Municipal de São Carlos, o Museu da Ciência e tecnologia Mário Tolentino e a Escola Estadual Paulino Carlos, além do monumento à Maurren Maggi, atleta olímpica de salto em distância que nasceu na cidade e medalhista de ouro na Olimpíada de Pequim em 2008. A praça é famosa por abrigar importantes eventos políticos e culturais, e originalmente era conhecida como "Largo Municipal" em 1883 por possuir desde as primeiras décadas da cidade diferentes prédios públicos. 


\section{ANÁLISE DAS PRAÇAS SEGUNDO OS CRITÉRIOS DE CULLEN E GEHL}

Assim, a partir dos critérios selecionados dos dois autores, analisou-se essas praças seguindo esses referenciais e obteve-se um quadro final resumindo a presença ou não desses elementos. Assim, elas puderam ser caracterizadas e definidas segundo o método utilizado: de acordo com o Quadro 1, com dez critérios de Cullen (1971) e sete critérios de Gehl (2010), e resultando no Quadro 3 final.

\subsection{Análise da praça Dr. Christiano Altenfelder Silva segundo os critérios de Cullen}

De acordo com os critérios de Cullen (1971) estudados, a praça Dr. Christiano Altenfelder Silva possui um vazio central (Figura 2a) que pode ser considerado um ponto focal visto que, em dias de exposições musicais e artísticas, é onde se concentram as atividades. É um espaço com o formato de um octógono, onde há um desnível demarcado com um diferente tipo de piso, sendo um ponto de convergência, apesar de não ser um símbolo vertical. Portanto, esse espaço atua como um ponto de encontro na praça. Dentro dela, as delimitações de espaço são feitas, particularmente, por canteiros, de diferentes estilos e tamanhos, que cercam espaços para flores, gramas e árvores e criam áreas de permeabilidade (Figura $2 \mathrm{~b}$ e $2 \mathrm{c}$ ).

Por ser contornada por quatro ruas com vários estabelecimentos comerciais, casas unifamiliares e edifícios, ela é fechada e não há a possibilidade de ver o longínquo. Assim, torna-se um recinto limitado, não possuindo o elemento entrelaçamento de Cullen (1971). Além disso, ao se adentrar na praça há a sensação de estreitamento definido por Cullen (1971), onde a paisagem é dividida em zonas definidas e diferenciadas das regiões ao redor. Este elemento proporciona uma sensação de surpresa aos pedestres, de forma que somente dentro do quadrilátero é possível ter a visão e conhecimento total da praça.

Apesar de não ter flutuação criada por edifícios, já que nessa região as ruas são uniformes e de grelhas ortogonais, em uma escala menor e restrita, os diferentes tipos de delimitações de espaços, causados por canteiros, árvores e mobiliários urbanos, provocam sequências na praça e alteram o caminho feito pelos pedestres, dando à praça uma flutuação em pequena escala. Além dessas delimitações, as árvores maiores provocam barreiras de visão e em algumas partes não há a visualização total do espaço, contribuindo também para o critério de flutuação nessa escala.

Por fim, excluindo os edifícios ao redor, não há no entorno nenhum edifício ou mobiliário (em tamanho menor) que tenha outra finalidade e se caracterize como uma forma de arte ou escultura atraindo a atenção dos pedestres. 


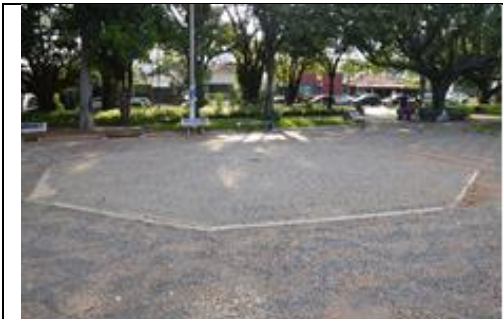

(a)

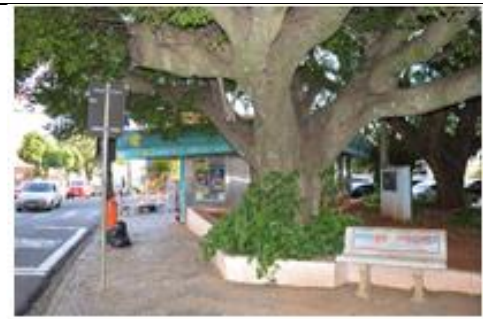

(b)

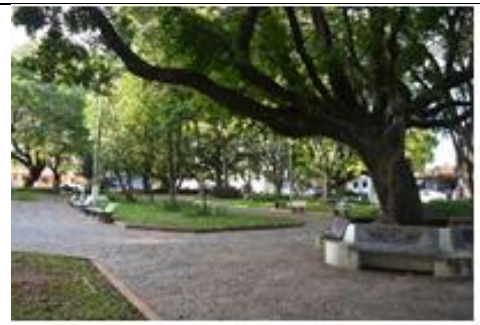

(c)

Fonte: AUTORES,2018

\subsection{Análise da praça Dr. Christiano Altenfelder Silva segundo os critérios de Gehl}

Analisando a praça pelos critérios de Gehl (2010), ela possui sobreposições de atividades noite e dia devido a diferentes edificações ao redor e é um ambiente público cheio de vida, onde as pessoas usam como passagem ou para sentar e apreciar o ambiente. Além disso, muitas edificações possuem uso misto, transformando a área em espaços de lazer e moradia. Há uma boa iluminação dando uma sensação de segurança e possibilitando aos pedestres que a atravessem mesmo no período noturno.

Além disso, ela é circundada por uma calçada e os canteiros no seu interior não impedem passagem de pedestres. E apesar de plana e não possuir obstáculos, a sua pavimentação é irregular e a manutenção deficiente (Figura 3a), atendendo apenas parcialmente o critério de boas superfícies de Gehl (2010). Em todas as esquinas há rampas e acessibilidade para os cadeirantes, porém não há piso tátil de alerta ou direcional e o pavimento não é adequado para a circulação de cadeirantes (Figura $3 \mathrm{~b}$ ). Há bancos que funcionam como lugar de descanso e a tornam uma zona atraente para sentar e descansar em meio às atividades urbanas, além de ser um refúgio do calor nos dias quentes devido à grande presença de arborização. Apesar do mobiliário urbano para sentar, estes apresentam disposição que desestimulam conversas entre os visitantes (Figura 3c).

Embora não possua mobiliários físicos que influenciem a atividade física, ginastica e jogos, o espaço central aberto propicia a oportunidade para brincar e praticar atividades. Portanto, a presença desse critério de Gehl (2010) é parcialmente atendida. Por fim, como as edificações ao redor da praça são baixas em comparação com as edificações comuns das cidades brasileiras, elas reivindicam à praça espaços projetados de acordo com a escala humana, atendendo ao critério de Gehl (2010) e de Cullen (1971) visto que, a partir de qualquer ponto dela, tem-se a percepção da dimensão dos edifícios e dos seus usos. 


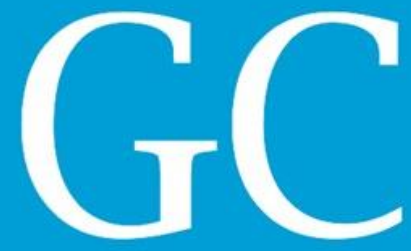

Revista Nacional de

Figura 3: Elementos observados na praça Dr. Christiano Altenfelder Silva: Condições da superfície (a), acessibilidade por rampas na praça (b) e disposição dos bancos na praça (c)

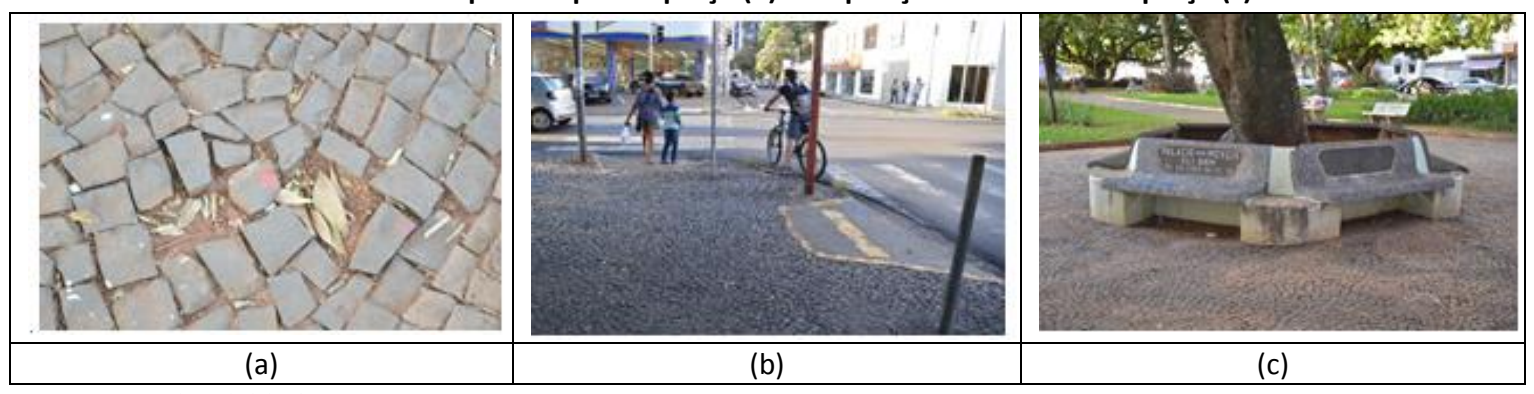

Fonte: AUTORES,2018

\subsection{Análise da praça Coronel Salles segundo os critérios de Cullen}

Na segunda praça analisada, a Praça Coronel Salles, há o ponto focal caracterizado por duas estruturas redondas de concreto presentes na lateral que, apesar de não serem elementos muito altos, caracterizam-se como pontos de encontro e de fácil localização (Figura 4a). Além disso, nela é possível visualizar a parte superior da Catedral de São Carlos, importante símbolo da cidade, permitindo que o pedestre se localize e assim, se caracterizando como um ponto focal de escala maior (Figura 4b).

As delimitações do espaço são caracterizadas por canteiros, pequenos muros, corrimões e diferentes desníveis, como escadarias e rampas, marcando diferentes espaços e usos. Observa-se que, como ela possui diferentes cotas altimétricas e a topografia decresce em direção à rua Major José Inácio, os desníveis possuem papel essencial na caracterização da praça Coronel Salles. A presença do museu na parte inferior, com a cota muito menor, confere ao museu um lugar isolado (Figura 4c). Além disso, a Câmara Municipal, posicionada na maior cota, exerce um papel importante e de onipresença (Figura 4d). Ao redor do ponto focal, nas estruturas redondas de concreto, a presença de uma escadaria e de um muro com oportunidade para sentar dão a essa área uma delimitação de espaço viável para a realização de eventos e de descanso (Figura 4e).

Apesar da parte de cima da catedral de São Carlos ser observada da praça, os elementos de entrelaçamento e de perspectiva grandiosa de Cullen (1971) não podem ser verificados, por ela ser fechada e sem a possiblidade de ver o longínquo. Em relação ao elemento de estreitamento de Cullen (1971), o pedestre que chega a ela pela rua Major José Inácio, a explora de uma perspectiva diferente: há a sensação de estreitamento, pois o pedestre não consegue adivinhar o que está acima do museu. Essa sensação de surpresa, também muito abordada no conceito de flutuação de Cullen (1971), é percebida somente nesse trecho (Figura 4f). Além disso, há quatro elementos e edifícios que podem ser caracterizados como escultura: a Câmara Municipal, a Bandeira do Brasil, a escultura à Maurren Maggi e o Museu. Todos eles 
Revista Nacional de Gerenciamento de Cidades

conferem outra finalidade e se caracterizam também como uma forma de arte atraindo a atenção dos pedestres.

Figura 4: Elementos observados na praça Coronel Salles: Estrutura de concreto na praça (a), Visão da catedral da praça (b), Isolamento do espaço do museu (c), Omnipresença da Câmara Municipal (d), Delimitações dos espaços com estruturas de concreto e escadarias (e), Flutuação - Perspectiva pela Rua Major José Inácio (f)

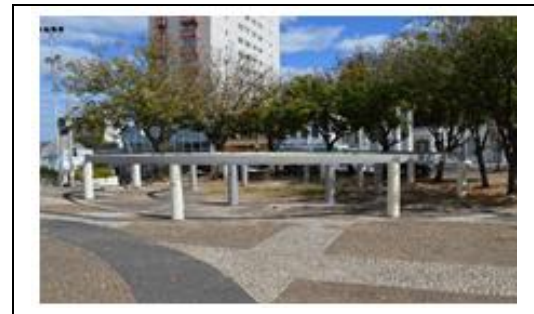

(a)

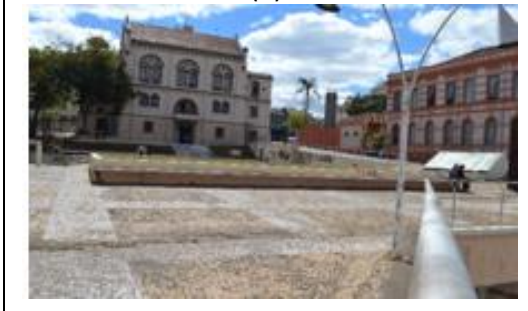

(d)

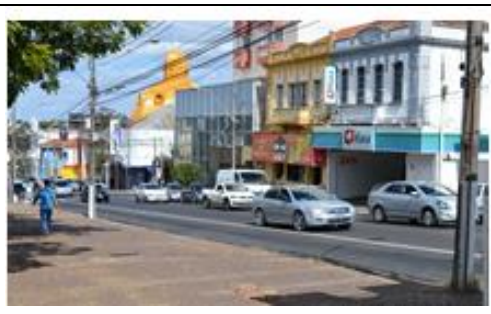

(b)

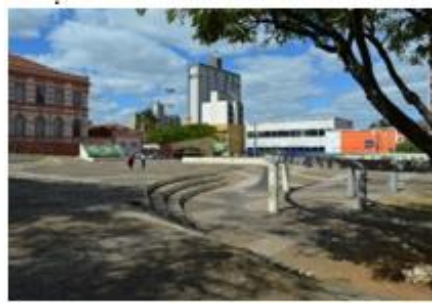

(e)

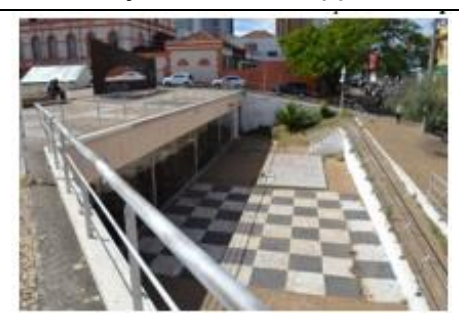

(c)

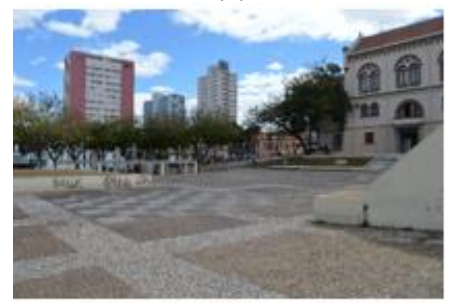

(f)

Fonte: AUTORES,2018

\subsection{Análise da praça Coronel Salles segundo os critérios de Gehl}

O entorno da praça Coronel Salles é constituído por diferentes tipos de usos, como comerciais e de serviços, diversificando as funções que os pedestres possuem ali. Ela funciona como passagem, lugar de repouso e como lugar de espera para o próximo ônibus, visto que ali abriga um ponto importante de conexão ao sistema de transporte público são-carlense. Porém essas atividades são majoritariamente diurnas, sem sobreposição de funções de dia e à noite e com ambiente público cheio de vida somente durante o dia. Na praça há iluminação pública, entretanto não há em toda a área, o que confere a ela uma característica de insegurança durante a noite. Além do mais, é circundada por uma calçada e por ser uma área bem ampla e aberta, há muito espaço para caminhar, embora ela não seja usada para esporte ou caminhadas diárias.

Apesar de não possuir obstáculos, a pavimentação da praça é irregular e sem manutenção, satisfazendo apenas parcialmente o critério de boas superfícies de Gehl (2010). Em todas as esquinas há rampas (Figura 5a) e acessibilidade para os cadeirantes, porém em relação a piso podo tátil (Figura $5 b$ ), há somente um pequeno trecho perto da câmara municipal. Além disso, os materiais escolhidos para o piso não são adequados para a circulação de cadeirantes, pois o assentamento da pedra portuguesa é muito irregular. Há locais para sentar, seja em forma do convencional banco ou em forma de outros mobiliários que servem como lugares de descanso, como escadaria, canteiros e pequenos muros. Eles a tornam uma zona atraente para sentar e descansar em meio às corriqueiras atividades urbanas. As formas como esses mobiliários se 


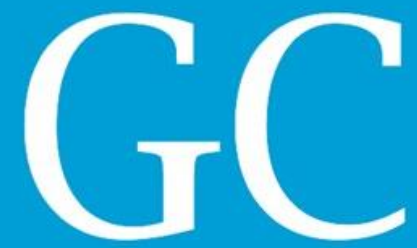

Revista Nacional de

comunicam dão a possiblidade para conversas entre os pedestres e é um agradável espaço para apreciar a paisagem urbana (Figura $5 c$ ). Porém, ela não possui zonas atraentes para permanecer em pé, visto que é uma área ampla e sem muita vegetação.

Embora não haja mobiliários físicos que influenciem a atividade física, ginastica e jogos, o espaço central, que possui um amplo espaço aberto, convida a presença dessas atividades, principalmente devido à existência de uma escola no entorno que atrai estudantes. É nesse espaço também que se realizam festivais e atividades, tornando-se a partir da presença de mobiliários intermitentes, convites para as atividades que Gehl (2010) expõe. Portanto, a presença desse critério é parcialmente atendida. Como as edificações no entorno são baixas em comparação com as edificações comuns das cidades brasileiras, elas reivindicam à praça espaços projetados de acordo com a escala humana, atendendo ao critério de Gehl (2010) e de Cullen (1971). A partir de qualquer ponto do espaço, tem-se a percepção da dimensão dos edifícios e dos seus usos.

Figura 5: Elementos observados na praça Coronel Salles: rampas (a), piso podo tátil (b), Espaço para sentar (c)

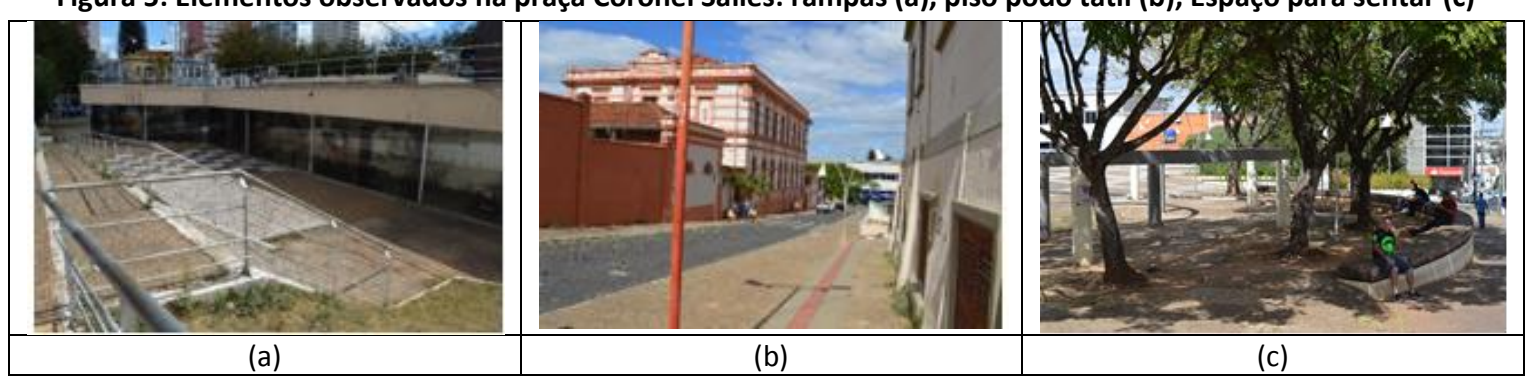

Fonte: AUTORES,2018

\section{DISCUSSÃO DE RESULTADOS}

A partir da caracterização e verificação dos critérios nos objetos de estudo, pode-se analisar a praça segundo os dois autores e criar um quadro resumindo a presença destes. Portanto, os itens a seguir buscam resumi-los e identificá-los de forma a criar subsídios para futuros projetos urbanos.

\subsection{Análise da praça Dr. Christiano Altenfelder Silva}

As análises feitas na praça Dr. Christiano Altenfelder Silva, a partir do tratado de estética urbanística de Cullen (1971) e dos critérios de qualidade de Gehl (2010), resultaram em uma tabela qualitativa do espaço público selecionado. O Quadro 3 apresenta os resultados, mostrando a presença ou não dos critérios escolhidos. Deste modo, é possível concluir por meio desse quadro que, em relação aos critérios de Cullen (1971), 60\% dos critérios foram atendidos e somente $30 \%$ não foram atendidos. E em relação aos critérios de Gehl (2010), $61,54 \%$ foram atendidos e $15,38 \%$ não foram atendidos. 
Os critérios não atendidos como entrelaçamento, perspectiva grandiosa e baixos níveis de ruídos se devem a localização da praça. Por ser construída nesse espaço limitado, não há a possibilidade de mudança de projeto para atendimento desses critérios. Porém, em relação aos critérios de edifício como escultura e de mobiliário urbano com disposição para conversas, por serem mudanças em escalas menores e não estruturais, são mudanças factíveis de se incluir no projeto. Já os elementos parcialmente atendidos, como boas superfícies e convites para criatividades, atividade física, ginástica e jogos, podem ser transformados em elementos atendidos sem maiores problemas. No primeiro caso, o atendimento se daria pela manutenção das superfícies e no segundo caso, como o atendimento parcial se dá pela presença esporádica de atividades físicas, musicais e feiras na praça, a presença regular mudaria o atendimento do critério. Por fim, atribui-se a essa análise um desempenho satisfatório da praça Dr. Christiano Altenfelder Silva em relação aos critérios de Cullen (1971) e Gehl (2010). 
Revista Nacional de

Quadro 3: Presença dos critérios na praça Dr. Christiano Altenfelder Silva

\begin{tabular}{|c|c|c|c|c|}
\hline \multirow{2}{*}{\multicolumn{2}{|c|}{$\begin{array}{c}\text { Critérios } \\
\text { GORDON CULLEN }\end{array}$}} & \multicolumn{3}{|c|}{ Presença do critério } \\
\hline & & \multirow{2}{*}{$\frac{\operatorname{sim}}{x}$} & \multirow[t]{2}{*}{ Parcialmente } & \multirow[t]{2}{*}{ Não } \\
\hline 1 & Ponto Focal & & & \\
\hline 2 & Delimitação do espaço & $\mathrm{x}$ & & \\
\hline 3 & Desníveis & & $\mathrm{x}$ & \\
\hline 4 & Entrelaçamento & & & $\mathrm{X}$ \\
\hline 5 & Perspectiva Grandiosa & & & $\mathrm{x}$ \\
\hline 6 & Estreitamentos & $\mathrm{x}$ & & \\
\hline 7 & Flutuação & $x$ & & \\
\hline 8 & Edifício como escultura & & & $\mathrm{x}$ \\
\hline 9 & Edifícios e espaços projetados de acordo com a escala humana & $\mathrm{x}$ & & \\
\hline 10 & Caminhos para pedestres & $\mathrm{x}$ & & \\
\hline & JAN GEHL & Sim & Parcialmente & Não \\
\hline 11 & Ambiente público cheio de vida & $\mathrm{x}$ & & \\
\hline 12 & Sobreposição de funções de dia e à noite & $x$ & & \\
\hline 13 & Boa iluminação & $\mathrm{x}$ & & \\
\hline 14 & Espaço para caminhar & $\mathrm{x}$ & & \\
\hline 15 & Ausência de obstáculos & $\mathrm{x}$ & & \\
\hline 16 & Boas superfícies & & $x$ & \\
\hline 17 & Acessibilidade & & $x$ & \\
\hline 18 & Presença de bancos para descanso & $\mathrm{x}$ & & \\
\hline 19 & Zonas atraentes para sentar-se & $\mathrm{x}$ & & \\
\hline 20 & Zonas atraentes para permanecer em pé & $\mathrm{x}$ & & \\
\hline 21 & Baixos níveis de ruídos & & & $x$ \\
\hline 22 & Mobiliário urbano com disposição para conversas & & & $\mathrm{x}$ \\
\hline 23 & Convites para criatividades, atividade física, ginástica e jogos & & $\mathrm{x}$ & \\
\hline
\end{tabular}

Fonte: AUTORES,2018

\subsection{Análise da praça Coronel Salles}

Já na análise da praça Coronel Salles, é possível concluir por meio do Quadro 4 a seguir que, em relação aos critérios de Cullen (1971), 60\% dos critérios foram atendidos e somente $20 \%$ não foram atendidos. E em relação aos critérios de Gehl (2010), 38,46\% foram atendidos e $23,08 \%$ não foram atendidos. Em ambos os casos, os critérios atendidos são a maioria, atendendo bem aos critérios propostos pelos autores.

Igual no caso da praça Dr. Christiano Altenfelder Silva, os critérios não atendidos como entrelaçamento, perspectiva grandiosa e baixos níveis de ruídos se devem a localização da 
praça. Por ser construída nesse espaço limitado, não há a possibilidade de mudança de projeto para atendimento desses critérios. Além disso, em relação aos critérios de sobreposição de funções de dia e à noite, ambiente público cheio de vida e convites para criatividades, atividade física, ginástica e jogos, a mudança pode ser feita incentivando o uso misto e de fachadas ativas dos edifícios e residências ao redor. Visto que a diversificação dos usos do solo e a democratização dos espaços atraem mais pedestres e usuários de serviços, aumentando a frequência diária.

Já os elementos parcialmente atendidos, como boas superfícies, acessibilidade e boa iluminação, podem ser transformados em elementos atendidos sem maiores problemas. No primeiro e segundo caso, o atendimento se daria pela manutenção das superfícies e instalação de pisos táteis e no terceiro caso, a instalação de novos postes e fontes de iluminação resolveriam o problema. Além disso, a inclusão de mais vegetação na praça, lugares para as pessoas apoiarem e de alguns recintos mais fechados melhorariam os critérios de zonas atraentes para sentar, estreitamentos e flutuação, respectivamente. Assim, atribui-se a essa análise um desempenho satisfatório da praça Coronel Salles em relação aos critérios de Cullen (1971) e Gehl (2010). Considerando-a como um exemplo de mudanças para outras praças de São Carlos e servindo como subsídios a outros espaços públicos brasileiros. 
Quadro 4: Presença dos critérios na praça Coronel Salles

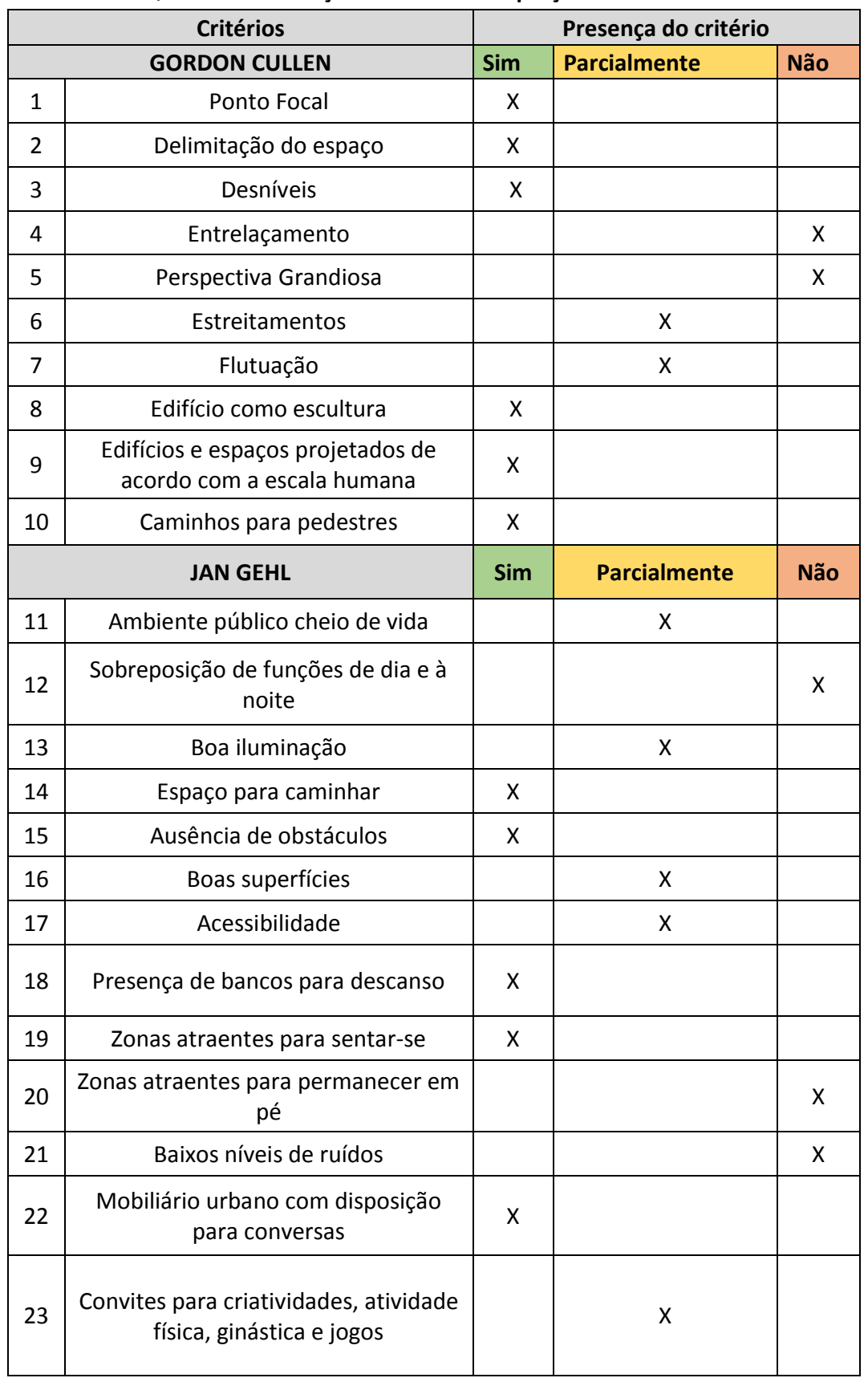

Fonte: AUTORES,2018

\section{CONSIDERAÇÕES FINAIS}

A aplicação de metodologias que buscam compreender a influência que o ambiente construído causa na percepção sensorial e nos usos dos usuários nesses objetos de estudo permitem detalhadamente descrever, entender e analisar o conjunto dos componentes que formam uma determinada avenida, um determinado bairro ou uma cidade. Assim, os elementos dos 
autores estudados e presenciados em outras cidades da Europa serviram como um guia para esse artigo e exemplificaram a integração desses elementos no meio urbano.

Dessa forma, a partir das análises das duas praças de São Carlos, pode-se observar o predominante atendimento de quase todos os critérios. Além disso, segundo o método adotado, a praça Dr. Christiano Altenfelder Silva possuiu melhor avaliação segundo os critérios estudados, comprovando a opinião popular de que ela é uma praça mais agradável e segura do que a praça Coronel Salles. E apesar de alguns não serem presentes ou possuírem atendimento parcial, eles são facilmente melhorados se algumas mudanças puderem ser feitas. Portanto, são diversos os fatores que impactam nas percepções sensoriais e nos usos dos usuários, conferindo a cada local uma identidade própria, ou seja, uma personalidade que destaca tal praça das demais. A partir dos casos explanados nesse trabalho, é possível compreender os critérios e o método, e assim aplicá-los também em outros ambientes de estudo, possibilitando comparações de percepções entre locais diferentes.

\section{REFERÊNCIAS}

CULLEN, Gordon. (1971). El Paisaje Urbano: tratado de estética urbanística. Tradução por José Maria Aymamí. Barcelona: Editorial Blume, 1974.

GEHL, Jan. (2010) Cidades Para Pessoas/ Jan Gehl; tradução Anita di Marco. 3 ed. São Paulo: Perspectiva, 2015.

GEHL, Jan. Life Between Buildings: Using Public Space; translate by Jo Koch. New York: Von Nostrand Reinhold. 1987.

SÃO CARLOS (MUNICÍPIO). Lei Municipal n 18.053, 19 de dezembro de 2016. Estabelece o Plano Diretor do Município de São Carlos e dá outras providências. São Carlos, 2016. 